\title{
PENERAPAN SELF-DIRECTED LEARNING MELALUI SISTEM PBL PADA MAHASISWA FAKULTAS KEDOKTERAN DI ASIA: SUATU KAJIAN LITERATUR
}

\author{
Nur Meity*, Titi Savitri Prihatiningsih**, Efrayim Suryadi** \\ * Fakultas Kedokteran Universitas Alkhairaat, Palu - INDONESIA \\ ** Fakultas Kedokteran Universitas Gadjah Mada, Yogyakarta - INDONESIA
}

\begin{abstract}
Background: Medical student need to develop self-directed learning skills in order to promote life-long learning skill which important for medical professionality. Rate of progression and innovation in science along with future medical world challenge incresingly strengthen self-directed learning and life-long learning as something that need to be noted. The importance of SDL can be discerned when American Board of Medical Specialties and World Federation for Medical Education put it as something that need to be evaluate in medical student during their time of study. The aims of this study is to gain explanation about self-directed learning implementation through PBL system and self-directed learning readiness in medical institutions in Asia.

Method: This study is a literature review, that is a study been held by searching, collect, analyze and summarize a number of articles concerning self-directed learning implementation through problem-based learning to medical students in Asia.

Results: Self-directed learning readiness medical students in Asia is found inferior, especially in first year students. In addition, self-directed learning implementation for Asian context, found that influence of lecturer exceedingly intense, where the right insight of self-directed learning will have an impact to succeed it implementation. Moreover, self-directed learning acquaintance have to be accompanied with accurate human resources management as well as support of facility and infrastructure, where the successfulness of self-directed learning implementation required entailment and commitment of all party.
\end{abstract}

Keywords: self-directed learning, problem-based learning, medical student, Asia

\begin{abstract}
ABSTRAK
Latar belakang: Mahasiswa kedokteran perlu mengembangkan kemampuan-kemampuan self-direcred learning agar bisa menumbuhkan keterampilan life-long learning yang penting bagi profesionalitas medis. Pesatnya kemajuan dan perubahan ilmu pengetahuan dan tantangan dunia kedokteran di masa depan semakin mengukuhkan self-directed learning dan life-long learning sebagai sesuatu yang harus diperhatikan. Pentingnya SDL bisa dilihat dari dimasukkannya SDL oleh American Board of Medical Specialties dan World Federation for Medical Education sebagai sesuatu yang harus dievaluasi pada mahasiswa kedokteran. Penelitian ini bertujuan untuk mendapatkan gambaran mengenai penerapan self-directed learning melalui sistem PBL di fakultas-fakultas kedokteran di Asia, dan mengenai self-directed learning readiness mahasiswa fakultas-fakultas kedokteran di Asia.

Metode: Penelitian ini merupakan penelitian suatu kajian literatur yaitu penelitian yang dilakukan dengan menganalisis sejumlah artikel yang membahas mengenai penerapan self-directed learning dalam pendekatan PBL pada mahasiswa fakultas-fakultas kedokteran di Asia.
\end{abstract}

Contact: meity.pasau@gmail.com 
Hasil: Self-directed learning readiness mahasiswa fakultas-fakultas kedokteran di Asia masih rendah, terutama pada mahasiswa tahun pertama. Sementara itu, penerapan Self-directed learning untuk situasi di Asia, peranan dan pengaruh Pendidik masih sangat kuat. Selanjutnya, pemahaman mengenai self-directed learning yang tepat akan sangat berpengaruh terhadap keberhasilan penerapannya, dimana pemaparan selfdirected learning sejak awal harus disertai dengan pengelolaan SDM yang tepat serta sarana dan prasarana yang mendukung. Selain itu, keberhasilan penerapan self-directed learning membutuhkan keterlibatan dan komitmen semua pihak.

Kata kunci: self-directed learning, problem-based learning, mahasiswa fakultas kedokteran, Asia

\section{PENDAHULUAN}

Problem-based learning (PBL) merupakan sebuah strategi pembelajaran yang telah diadopsi oleh fakultas-fakultas kedokteran dan juga institusiinstitusi pendidikan kesehatan lainnya di seluruh dunia termasuk Indonesia. ${ }^{1,2}$ Keutamaan PBL dalam proses belajar mengajar karena PBL memusatkan perhatian yang lebih untuk mengembangkan kemampuan mahasiswa ke arah self-directed learner. ${ }^{3}$

Mahasiswa fakultas kedokteran perlu mengembangkan kemampuan-kemampuan self-direcred learning agar bisa menumbuhkan keterampilan life-long learning yang penting bagi profesionalitas medis. ${ }^{4,5}$ Pesatnya kemajuan dan perubahan ilmu pengetahuan dan tantangan dunia kedokteran di masa depan semakin mengukuhkan self-directed learning dan life-long learning sebagai sesuatu yang harus diperhatikan. ${ }^{6,7}$ Pentingnya SDL bisa dilihat dari dimasukkannya SDL oleh American Board of Medical Specialties dan World Federation for Medical Education sebagai sesuatu yang harus dievaluasi pada mahasiswa fakultas kedokteran. ${ }^{5}$

Akan tetapi, penggunaan sistem PBL tidak langsung menentukan bahwa penerapan self-directed learning bisa terjadi secara bersamaan melainkan harus melalui proses, usaha serta bimbingan secara berkelanjutan untuk mewujudkannya. ${ }^{8}$ Modifikasi yang tepat dibutuhkan demi kesuksesan aplikasi metode yang baru sesuai dengan kondisi masingmasing tempat. ${ }^{9-11}$

\section{METODE}

Jenis penelitian ini merupakan penelitian literatur review yaitu penelitian yang dilakukan dengan menganalisis sejumlah artikel yang membahas mengenai penerapan self-directed learning melalui pendekatan PBL pada mahasiswa fakultas-fakultas kedokteran di Asia.

Artikel-artikel yang membahas mengenai selfdirected learning dalam tinjauan ini didapatkan dari beberapa sumber data online seperti Pubmed, Medline dan Scopus. Terminologi yang digunakan saat melakukan pencarian artikel yaitu self-directed learning, problem-based learning, medical students, dan Asia. Terminologi ini digunakan secara sendiri maupun kombinasi dengan self-directed learning sebagai judul subjek utama atau diinput sebagai text word in titles dan kata lainnya sebagai text word in titles juga atau abstract. Didapatkan sejumlah artikel dari pencarian tersebut yang kemudian diseleksi berdasarkan kriteria inklusi sebagai berikut: a) merupakan artikel yang membahas mengenai selfdirected learning dalam konteks PBL pada mahasiswa kedokteran di wilayah Asia; b) artikel-artikel ini dipublikasikan dari tahun 2006 sampai 2016; c) artikel-artikel ini ditulis dalam bahasa Inggris atau bahasa Indonesia. Sebagai hasilnya, didapatkan 12 artikel yang telah melewati proses eksklusi dengan menggunakan pedoman penilaian artikel dari Luc Cote dan Jean Turgeon, Department of Family Medicine, Faculty of Medicine, Laval University, Quebec, Canada ${ }^{12}$ dan diolah berdasarkan skema pengolahan data yang telah disusun.

Keseluruhan artikel yang didapatkan akan di analisis dalam tiga tahapan, yaitu:

1. Tahap 1, pendataan permasalahan penelitian, tujuan penelitian, hasil penelitian, pernyataanpernyataan penting dan penyusunan kesimpulan. 
2. Tahap 2, pengelompokan hasil-hasil dari tahap 1 , penentuan tema-tema, pengidentifikasian persamaan tiap tema dan pengelompokkan tema-tema.
3. Tahap 3, pengidentifikasian pokok-pokok pembahasan dan penetapan pokok-pokok pembahasan.

Tahap 2a

Mengelompokkan:

- Hasil penelitian

- Pernyataan-pernyataan penting

- Kesimpulan secara keseluruhan

Tahap 1a

Mendata:

- Permasalahan penelitian

- Tujuan penelitian

- Hasil penelitian

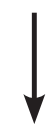

Tahap $1 \mathrm{~b}$

$$
\begin{aligned}
& \text { Mendata pernyataan- } \\
& \text { pernyataan penting }
\end{aligned}
$$

Artikel-artikel yang ditinjau
Tahap 3a

Tahap 2b

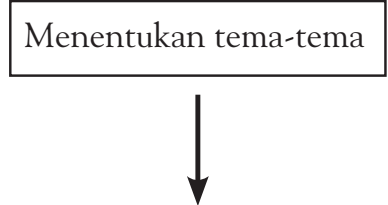

Tahap 2c

Mengidentifikasi persamaan tiap tema
Identifikasi pokok-pokok pembahasan

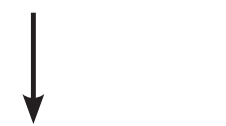

Tahap 3b

Penetapan pokok-pokok pembahasan

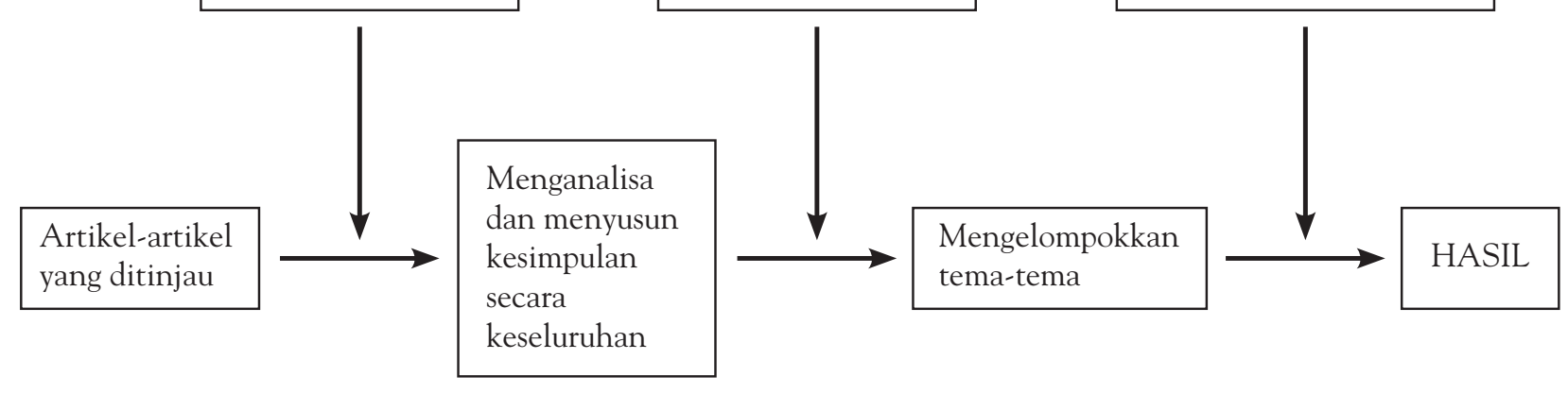

Gambar 1. Skema Pengolahan Data

\section{HASIL DAN PEMBAHASAN}

\section{Self-directed Learning Readiness Mahasiswa Fakultas Kedokteran di Asia}

Secara umum dari tinjauan keseluruhan artikel, bila merujuk pada pengertian self-directed learning oleh Knowles beserta tujuh kompetensi self-directed learner maka bisa disimpulkan bahwa mahasiswa kedokteran di Asia tahun pertama dan kedua belum bisa menerapkan self-directed learning. Sedangkan ketika memasuki tahun ketiga dimana mereka telah belajar beradaptasi dan memahami keuntungan hal tersebut untuk dirinya, maka dengan cepat perilaku belajarnya berubah. ${ }^{7,10,13,14}$
Readiness dalam self-directed learning diartikan sebagai tahapan dimana seseorang memiliki sikap, cara berpikir, kemampuan dan kepribadian khusus yang dibutuhkan untuk menjadi self-directed learner. ${ }^{14,19}$

Nilai SDLR mahasiswa pada awal masuk dengan akhir tahun pertama mengalami peningkatan yang tidak bermakna mungkin dikarenakan rentang waktu menghitungnya hanya sekitar satu tahun. Hal ini bisa dipahami karena pada awal masuk dan terpapar dengan sistem PBL, pada dasarnya mahasiswa perlu beradaptasi dengan sistem pembelajaran baru. ${ }^{6,8}$ 
Pengukuran nilai SDLR mahasiswa fakultas kedokteran di Amerika Utara didapatkan nilai SDLR yang lebih tinggi dari rata-rata nilai populasi dewasa. Hasil tersebut di atas sangat berbeda dengan yang didapatkan pada mahasiswa fakultas kedokteran di Asia dimana nilai SDLR di awal masuk rendah tetapi kemudian mengalami peningkatan di akhir tahun pertama walau tidak terlalu bermakna dan mengalami peningkatan yang signifikan setelah tiga tahun. Nilai SDLR mahasiswa di Amerika Utara terus menurun seiring dengan tahun pembelajaran di Fakultas Kedokteran (diukur setiap tahun), bahkan sampai tahun keempat tetapi tetap berada di atas rata-rata nilai populasi dewasa. ${ }^{5}$

Hasil yang berbeda juga didapatkan dari hubungan antara nilai SDLR dengan jenis kelamin dimana pada mahasiswa di Amerika Utara tidak ditemukan perbedaan nilai SDLR berdasarkan jenis kelamin ${ }^{5}$, sedangkan pada dua penelitian di Asia ${ }^{7,14}$ didapatkan perbedaan nilai. Pada mahasiswa di luar Amerika Utara, perbedaan usia mempengaruhi nilai SDLR meskipun diakui bahwa hasilnya bervariasi, dimana mahasiswa yang lebih tua usianya memiliki nilai SDLR yang lebih tinggi. ${ }^{5,20}$

\section{Pemahaman mengenai Self-directed Learning}

Beberapa penelitian yang ditinjau, menyatakan adanya kesalahan pemahaman pengertian SDL yang terjadi pada mahasiswa, dosen dan bahkan pihak fakultas. ${ }^{7,9,11}$

Hal ini bisa dilihat dari beberapa pernyataan berikut:

- Mahasiswa ingin fakultas menentukan dengan jelas mengenai hal yang harus dilakukan mahasiswa dalam waktu yang dialokasikan untuk SDL,

- Mahasiswa mengisi waktu yang dialokasikan untuk SDL dengan kegiatan non akademik

- SDL dianggap sama dengan self study dan independent learning.

Pemahaman yang salah mengenai definisi selfdirected learning bisa menimbulkan definisi baru yang terkadang memiliki arti dan makna sangat berbeda dengan arti sebenarnya dan akhirnya menimbulkan permasalahan dalam penerapannya. Kesalahan pemahaman mengenai definisi SDL ini bukan hanya dialami oleh dosen dan pihak fakultas tetapi juga oleh mahasiswa. ${ }^{21-25}$

Beberapa artikel dalam tinjauan literatur ada yang menyamakan SDL dengan self-study dan menganggapnya sebagai sesuatu yang memang hanya untuk mahasiswa. Hal ini dialami oleh dosen, fakultas maupun mahasiswa itu sendiri, sehingga dalam penerapannya diserahkan sepenuhnya kepada mahasiswa. ${ }^{11,13}$ Penyamaan definisi SDL dengan self studi juga ditemukan pada mahasiswa keperawatan yang menimbulkan pemahaman bahwa waktu yang disediakan untuk SDL artinya waktu untuk terbebas dari rutinitas proses pembelajaran. ${ }^{21}$

Penting bagi pihak fakultas untuk mencari solusi perbaikan masalah tersebut dan mengawalinya dengan menjelaskan dan memahamkan kepada seluruh staf mengenai konsep SDL yang sebenarmya sehingga bisa memberikan dukungan serta bimbingan yang tepat kepada mahasiswa dalam proses penerapannya. ${ }^{22}$

\section{Peran Mahasiswa Sebagai Pembelajar}

Ada 5 tema yang teridentifikasi dari hasil pengolahan data, yaitu:

1. Mahasiswa masih berorientasi pada ujian (peran assessment) $)^{8,10,12}$

2. Mahasiswa masih mengharapkan pendidik untuk memberikan/ mendapatkan ilmu (ketergantungan terhadap pendidik) ${ }^{8,15}$

3. Latar belakang pendidikan mahasiswa ${ }^{6,8,9}$

4. Karakteristik demografi dan latar belakang mahasiswa $^{7,10}$

5. Memiliki pemahaman yang jelas mengenai SDL.

Berdasarkan tingkat SDL, mahasiswa bisa dikelompokkan menjadi 4 kelompok yaitu ${ }^{14}$ :

1. Dependent learners.

2. Student capable of moderate self-direction, dikategorikan "available", "interested" atau "interestable".

3. Student at intermediate self-direction.

4. Student capable of high self-direction. 
Motivasi serta pengetahuan mahasiswa mengenai kemampuannya sendiri sangat menentukan dimana posisinya pada tingkatan pembelajar. ${ }^{10,14}$ Sikap mahasiswa yang masih berorientasi pada nilai dan ujian dan masih mengharapkan dosen untuk mendapatkan pengetahuan bisa mempengaruhi motivasinya untuk menerapkan SDL. 2,20,22

Sebagai individu yang diharapkan bisa menerapkan SDL dalam kesehariannya, maka peran utama yang bisa mendukung maupun menghambat proses penerapan SDL adalah mahasiswa itu sendiri dengan karakteristiknya, motivasinya, kemandiriannya, rasa ingin tahunya, rasa tanggung jawabnya dan keinginannya untuk sukses. 5,13,22,25 Mahasiswa yang bisa melakukan refleksi terhadap kemampuan selfdirected learning nya, cenderung memodifikasinya dan akhirnya menerapkan strategi SDL yang lebih baik serta cocok untuk dirinya. ${ }^{6,10,16}$

Hasil tinjauan literatur dimana mahasiswa fakultasfakultas kedokteran di Asia yang tidak terpapar dengan SDL sebelumnya mendapatkan kesulitan untuk beradaptasi dengan lingkungan perkuliahan yang menekankan pada penerapan SDL, ternyata hal ini ditemukan juga pada mahasiswa fakultas kedokteran di luar Asia dan mahasiswa fakultas kesehatan yang lain meskipun mereka telah terpapar dengan SDL sebelumnya. ${ }^{2,5,26}$ Masalah latar belakang pendidikan yang tidak terpapar dengan SDL sebenarnya bisa di atasi dengan pengenalan dan papaparan berkelanjutan mengenai SDL kepada mahasiswa akan tetapi hal ini membutuhkan SDM dan sarana serta prasarana yang menunjang. Karena pada kenyataannya, kebanyakan mahasiswa/ kelompok berdasarkan latar belakang pendidikan sebelumnya, membutuhkan bimbingan untuk bisa beradaptasi setidaknya sampai dia menyadari dirinya memiliki kemampuan untuk menghadapi situasi tersebut. ${ }^{16}$

\section{Peran Dosen Sebagai Pendidik}

Ada 3 tema yang penulis dapatkan dari hasil pengolahan data, sebagai berikut:

1. Latar belakang pendidikan dosen. ${ }^{6,9}$

2. Bertanggung jawab, kompeten dan memiliki kepedulian terhadap mahasiswa. ${ }^{10,13,14}$

3. Memiliki pemahaman yang jelas mengenai SDL.
Di wilayah Asia maupun di Barat, pengaruh pendidik ini tetap tidak bisa diabaikan bahkan pada mahasiswa yang dianggap sudah bisa menerapkan SDL. Di barat, walaupun SDL dalam PBL bukan lagi sesuatu yang baru bagi mahasiswa karena telah terpapar dengan sistem tersebut sejak sebelum masuk kuliah, mahasiswa pun masih mengandalkan dosen untuk mendapatkan pengetahuan. ${ }^{8}$

Pengelompokan pembelajar berdasarkan tingkat self-directed learning menunjukkan bahwa pendidik berperan dalam tahapan membawa seorang mahasiswa yang dependent learner untuk menjadi seorang mahasiswa yang self-directed learner. $7,10,13,14,16$

Pemahaman seorang pendidik mengenai tingkat SDLR mahasiswa, tingkat kebutuhan SDL mahasiswa dan kepercayaan diri mahasiswa akan kemampuan SDL nya, akan memudahkannya untuk menempatkan diri secara tepat dalam proses pembelajaran mahasiswa. ${ }^{7,11,13,14,16}$

Pendidik yang memiliki pemahaman yang benar mengenai SDL dan menerapkan SDL dalam kesehariannya akan bisa menemukan cara yang tepat serta bisa menempatkan diri dengan baik untuk mendorong SDL mahasiswa. Pendidik yang self-directed mengerti bahwa SDL adalah suatu kemampuan yang harus dikembangkan sendiri secara perlahan-lahan oleh seseorang melalui proses pembelajarannya dan kemampuan ini tidak bisa diajarkan..$^{21-24}$

Peran pendidik maupun fakultas untuk mendukung pengembangan SDL mahasiswa adalah dengan membimbing mahasiswa untuk mempelajari keterampilan-keterampilan belajar yang mendukung SDL dan menyediakan sarana prasarana yang mendukung proses pembelajarannya. ${ }^{5} \mathrm{Hal}$ ini harus dilakukan secara berkelanjutan sampai mahasiswa menguasai keterampilan-keterampilan belajar tersebut yang kemudian memungkinkannya untuk melakukan semua proses tersebut secara mandiri.

\section{Peran Fakultas Sebagai Pengelola}

Ada 5 tema yang teridentifikasi dari hasil pengolahan data, yaitu:

1. Bimbingan dan pelatihan-pelatihan yang mendukung SDL ${ }^{6-8,10,15-17}$ 
2. Kebijakan fakultas mengenai sistem baru ${ }^{9-11}$

3. SDM, sarana dan prasarana ${ }^{9,11,15-18}$

4. Manajemen fakultas dalam mengelola proses pembelajaran $^{6,7,10,14}$

5. Pemahaman yang jelas mengenai SDL.

Manajemen fakultas dalam mengelola proses pembelajaran menjadi tolak ukur keberhasilan institusi dari segala aspek..$^{7-10,14}$ Visi dan misi fakultas akan mengarahkan kebijakan-kebijakan yang ditetapkan serta program-program yang dijalankan menuju pencapaian keberhasilan dengan mahasiswa sebagai pusat dari semua aktivitas. ${ }^{7,14,15,26}$

Strategi kurikulum yang baik akan mendorong penerapan SDL. ${ }^{5}$ Kesiapan sarana dan prasarana serta inovasi dalam alat bantu pembelajaran juga bisa mendorong pelaksanaan SDL. ${ }^{21,24,25,27}$ Jika dalam artikel tinjauan literatur ditemukan penggunaan study guide mendorong pelaksanaan SDL, maka Tolsgaard et al, 2013 menggunakan CECs (clinical encounter-cards) untuk mendorong pelaksanaan SDL mahasiswa fase klinik sedangkan Van Schaik et al menggunakan portfolio untuk membangun SDL mahasiswa fase akademik. ${ }^{25}$

Fakultas harus bisa menempatkan diri sebagai partner belajar mahasiswa yang siap untuk memfasilitasi semua kebutuhan mahasiswa dalam proses pembelajarannya, memberikan pemahaman yang tepat mengenai proses belajar yang akan dijalani, serta membekali mahasiswa dengan keterampilan-keterampilan yang dibutuhkan selama pendidikan. 3,7,15,17,21,22 Selain pembekalan dengan keterampilan-keterampilan yang mendukung proses belajar dan penerapan SDL, bimbinganbimbingan juga diperlukan oleh mahasiswa untuk melewati proses adaptasi dengan suasana yang baru. Premkumar et al, 2013 menemukan dalam penelitiannya bahwa seseorang yang sangat selfdirected pun, jika dihadapkan pada keadaan baru dan tidak biasa baginya akan menjadi kurang selfdirected. 5,20

Mengetahui nilai dan tingkat SDLR mahasiswa, memahami kepercayaan diri mahasiswa akan kemampuan self-directed learning nya akan membantu fakultas untuk menyusun program pelatihan maupun menyediakan sarana penunjang yang sesuai untuk mendukung proses pembelajaran mahasiswa. ${ }^{9} 10,13,14$

\section{Pengaruh Lingkungan Sosial dan Budaya}

Pengaruh lingkungan sosial dan budaya merangkum situasi mahasiswa sehubungan dengan:

1. Suku yang terkadang menyebabkan kendala bahasa. ${ }^{9}$

2. Tradisi untuk menghormati cara-cara yang lama sehingga menimbulkan kekhawatiran akan perubahan. ${ }^{8}$

3. Budaya masyarakat yang senang berkompetisi dan penghargaan terhadap keberhasilan. ${ }^{8}$

4. Hirarki yang menimbulkan penghargaan serta kepercayaan kepada orang yang lebih tua, ahli maupun yang memiliki status tinggi yang menyebabkan kurang percaya terhadap pendapat sendiri dan pendapat rekan diskusi. ${ }^{8}$

Tradisi dan kebudayaan memang berpengaruh terhadap proses belajar mahasiswa dimana mahasiswa Asia yang sangat menghargai tradisi dan budaya membuat mereka turut bertoleransi untuk tidak mengadopsi sistem baru yang tidak disambut oleh orang-orang yang mereka anggap sebagai panutan. ${ }^{6,8,9}$ Pengaruh budaya rasa hormat kepada orang yang lebih tua maupun orang yang lebih tinggi kedudukannya akan menyebabkan mahasiswa mendengarkan pandangannya dan mengikuti pandangan-pandangannya. ${ }^{28} \quad$ Kecendrungan ini mengakibatkan mahasiswa tidak terbiasa mendengarkan pendapat teman diskusi bahkan kadang tidak percaya diri terhadap pendapatnya sendiri. ${ }^{8}$

Mahasiswa yang self-directed seharusnya bisa mencari, mengelola serta menentukan sendiri kebutuhan belajarnya, tetapi lingkungan sosial budaya bisa membatasi keleluasaannya dalam bersikap dan bisa mempengaruhi sikap serta tingkah laku nya dalam menentukan arah pembelajaran. ${ }^{6}$ Hal ini juga akan semakin memburuk bila tidak didukung oleh sumber belajar yang bisa diakses secara mandiri. ${ }^{15,17,18}$

Pengaruh lingkungan sosial budaya ini bisa diminimalisirdengan pemaparan self-directedlearning 
sejak awal dan dilakukan secara berkelanjutan dengan didukung oleh sarana prasarana yang memadai, pendidik yang self-directed dan yang terpenting adalah pembekalan keterampilanketerampilan yang dibutuhkan mahasiswa untuk mendukung proses pembelajarannya. ${ }^{15-18}$

Dikarenakan keterbatasan waktu dan biaya yang dialami penulis dalam melakukan tinjauan literatur ini, maka penulis membatasi pencarian literatur hanya dengan metode pencarian dan media yang bisa diakses secara online melalui internet.

\section{KESIMPULAN}

Berdasarkan hasil tinjauan literatur ini, dapat diambil kesimpulan bahwa self-directed learning readiness mahasiswa fakultas kedokteran di Asia masih rendah, terutama pada mahasiswa tahun pertama. Hal ini berhubungan dengan penerapan Self-directed learning untuk situasi di Asia, dimana peranan dan pengaruh Pendidik masih sangat kuat. Selain itu, pemahaman mengenai self-directed learning yang tepat akan sangat berpengaruh terhadap keberhasilan penerapannya. Pemaparan self-directed learning sejak awal harus disertai dengan pengelolaan SDM yang tepat serta sarana dan prasarana yang mendukung. Keberhasilan penerapan self-directed learning membutuhkan keterlibatan dan komitmen semua pihak baik mahasiswa itu sendiri, pendidik maupun pihak fakultas.

\section{DAFTAR PUSTAKA}

1. Azer, SA. Problem-based learning in the fifth, sixth, and seventh grades: assessmenent of student perception. Teaching and Teacher Education, 2009;25:1033-42.

2. Bidokht M, Assareh A. Life-long learners through problem-based and self-directed learning. Science Direct, 2011;3:1446-53.

3. Harun NF, Yusof KM, Jamaludin MZ, Hasan SAHS. Motivation in problem-based learning implementation. Procedia - Social and Behavioral Sciences, 2012;56:233-42.

4. Zhang J, Peterson RF, Ozolins LZ. Student Approach for Learning in Medicine: What does It Tell Us About The Informal Curriculum. BMC Medical Education, 2011;11(87):1-9.
5. Premkumar K, Pahwa P, Banerjee A, Baptiste K, Bhatt H, Lim HJ. Does Medical Training Promote or Deter Self-directed Learning? A Longitudinal Mixed-methods Study. Academic Medicine, 2013;88(11):1754-64.

6. Elzubeir MA. Graduate-entry Medical Students' Self-directed Learning Capabilities in a problembased Curriculum. Saudi Med J, 2009;30(9):1219. 24.

7. Shankar PR, Bajracharya O, Jha N, Gurung SB, Ansari SR, Thapa HS. Change in Medical Students' Readiness for Self-directed Learning After a Partially Problem-based Learning First Year Curriculum at the KIST Medical College in Lalitpur, Nepal. Education for Health, 2011;24(2):1-10.

8. Frambach JM, Driessen EW, Chan LC, Van der Vleuten CPM. Rethinking the globalisation of problem-based learning: how culture challenges selfdirected learning. Medical Education, 2012;46:738-47.

9. Ghosh S. Combination of Didactic Lectures and Case-oriented Problem-solving Tutorials Toward Better Learning : Perceptions of Students from a Conventional Medical Curriculum. Advan in Physol Edu, 2007;31:193-7.

10. Oda M, Koizumi S. Status of medical education reform at saga medical school 5 years after introducing PBL. Kaohsiung J Med Sci, 2008;24(3):546-53.

11. Al-Shobaili HA, Al-Robaee AA, Al-Zolibani AA, Gabbani SA, Sharaf FK. Utilization of Self-directed learning Allocated Times by Medical Students. Saudi Med J, 2009;31(3):332-5.

12. Cote L, Turgeon J. Appraising qualitative research articles in medicine and medical education. Medical Teacher, 2005;27(1):71-5.

13. Tsou KI, Cho SL, Lin CS, Sy LB, Yung LK, Chou TY, Chiang HS. Short-term Outcomes of A Nearfull PBL Curriculum in a New Taiwan Medical School. Kaohsiung J Med Sci, 2009;25(5):282-93.

14. Kar SS, KC Premajan, Ramalingam A, S Iswarya, A Sujiv, L Subitha. Self-directed learning readiness among fifth semester MBBS students in a teaching institution of South India. Education for Health, 2014;27(3):289-92.

15. Leong KC, Teng CL, Ng CJ. Learning resources and activities: students' feedback from two malaysian medical school. Med J Malaysia, 2007;62(3):265-7

16. Tagawa M, Imanaka H. Reflection and Self-directed and Group Learning Improve OSCE Scores. The Clinical Teacher, 2009;7:266-70.

17. Mafinejad MK, Aghili R, Emami Z, Malek M, Baradaran $\mathrm{H}$, Taghavinia $\mathrm{M}$, \& Khamseh ME. 
Study Guides : Effective Tools to Improve Selfdirected Learning Skills of Medical Students. Acta Medica Iranica, 2014;52(10):781-5.

18. Maung M, Abdullah A, Abas ZW. Appreciation of learning environment and development of higher-order learning skills in a problem-based learning medical curriculum. Med J Malaysia, 2011;66(5):435-9.

19. Fisher M, King J, Tague G. Development of a self-directed learning readiness scale for nursing education. Nurse Education Today, 2001;21:516-25.

20. Bengtsson $\mathrm{M}$, Ohlsson $\mathrm{B}$. The nursing and medical students motivation to attain knowledge. Nurse Education Today, 2010;30:150-6.

21. Hewitt-Taylor J. Self-directed Learning: Views of Teacher and Students. Journal of Advanced Nursing, 2001;36(4):496-504.

22. Regan A. Motivating student towards self-directed learning. Nurse Education Today, 2003;23:593-9.

23. Levett-Jones TL. Self-directed learning: implications and limitations for undergraduate nursing education. Nurse Education Today, 2005;25:363-8.
24. Loyens SMM, Magda J, Rikers RMJP. Selfdirected learning in problem-based learning and its relationship with self-regulated learning. Educ Psychol Rev, 2008;20:411-27.

25. Van Schaik S, Plant J, O'Sullivan P. Promoting Self-directed Learning Through Portfolios in Undergraduate Medical Education: The Mentors' Perspective. Medical Teacher, 2013;35:139-44.

26. Mann, KV. Motivation in medical education: how theory can inform practice. Academic Medicine, 1999;74(3):237-9.

27. Idros SNS, Mohamed AR, Esa N, Samsudin MA, Daud KAM. Enhancing Self-directed Learning Skills Through e-SOLMS for Malaysian Learners. Procedia Social and Behavioral Sciences, 2010;2:698. 706.

28. Ahmad BE, Majid FA. Self-directed Learning and Culture: A Study on Malay Adult Learners. Procedia Social and Behavioral Sciences, 2010;7(C):254-63. 